Does brown adipose tissue have a role to play in glucose homeostasis?

By M. A. Cawthorne, Beecham Pharmaceuticals Research Division, Great Burgh, Yew Tree Bottom Road, Epsom, Surrey KT18 $5 X Q$

Obesity and type II diabetes co-exist within the same population and the term 'diabesity' has been coined to cover this vast group of patients. First-line therapy is a prudent low-fat, high-fibre diet together with an increase in the level of exercise. This therapy is designed to restore body-weight to normal and improve the insulin sensitivity of peripheral tissues, particularly muscle.

James \& Trayhurn (1976) developed the hypothesis that energy expenditure on regulatory non-shivering thermogenesis made a significant contribution to overall energy expenditure, and variations in this component might be important in explaining the variable propensity to obesity in both man and animals. Since then, in a range of animals including $o b / o b$ mice, $d b / d b$ mice, falfa rats and mice given gold thioglucose, the co-existence of insulin resistance and obesity has been demonstrated. In each case, evidence has been obtained of early changes in both variables, before overt obesity. Another example of this correlation is the rat fed on a cafeteria-type diet. Rothwell \& Stock $(1982,1983)$ demonstrated that obesity is resisted in young rats but not in old rats. As shown in Table 1, young rats fed on a cafeteria diet show enhanced insulin sensitivity, as measured by the glucose disposal rate following intravenous administration of insulin, whereas old rats are insulin resistant. In human studies, Golay et al. (1986) found a correlation in a range of subjects between thermic response to a $100 \mathrm{~g}$ oral glucose load and insulin-mediated glucose uptake under euglycaemic-clamp conditions.

\title{
Glucose metabolism in brown adipose tissue
}

The observation in rodents that brown adipose tissue is the most important site of non-shivering thermogenesis (Thurlby \& Trayhurn, 1979, 1980; Trayhurn, 1979) and also possesses high activities of the enzymes of glycolysis (Cooney \& Newsholme, 1982; Young et al. 1984) and pyruvate dehydrogenase (McCormack \& Denton, 1977), led to the possibility that blood glucose might be used directly as a thermogenic fuel and, hence, be involved in the regulation of blood glucose concentration (Cooney \& Newsholme, 1984).

\section{Table 1. Glucose decay rates in young and old rats fed on a cafeteria diet}

(Young rats were 5 weeks old at the start of the experiment and old rats were 9-12 weeks old. Diets were provided for 3 weeks and then the rats were fasted for $5 \mathrm{~h}$ before receiving $400 \mathrm{mU}$ insulin (Actrapid, Novo) $/ \mathrm{kg}$ intravenously. Blood samples were obtained at $5 \mathrm{~min}$ intervals for glucose analysis and the fractional glucose decay rate was calculated)

\begin{tabular}{lllc} 
& & \multicolumn{2}{c}{ Glucose decay $(\% / \mathrm{min})$} \\
\cline { 3 - 4 } Age of rat & Diet & Mean & SD \\
Young & Chow & 3.41 & 1.08 \\
Old & Chow & 3.46 & 1.65 \\
Young & Cafeteria & 4.76 & 1.11 \\
Old & Cafeteria & $2.75^{*}$ & 0.93
\end{tabular}

*Decay rate was significantly different from that in young rats fed on the cafeteria diet: $P<0.05$. 
This possibility was further supported by the finding that the maximal activities of hexokinase and phosphofructokinase in brown adipose tissue are increased under conditions of increased thermogenesis and insulin sensitivity such as cold-acclimation (Cooney \& Newsholme, 1984), and reduced in insulin-resistant, glucose-intolerant animals such as $o b / o b$ and $d b / d b$ mice (Young et al. 1984), which also have defective non-shivering thermogenesis.

Further evidence was provided by the finding that a novel type of $\beta$-adrenoceptor agonist, such as BRL 26830 and BRL 35135, which interacts selectively with the atypical $\beta$-adrenoceptor in brown adipose tissue, thereby producing an anti-obesity action by stimulating thermogenesis (Arch et al. 1984), also has antihyperglycaemic activity when dosed chronically to insulin-resistant $d b / d b$ and ob/ob mice (Carroll et al. 1985; Sennitt et al. 1985). The improvement in glycaemic control in these mice is associated with increases in the maximal activities of hexokinase and phosphofructokinase, which provide a quantitative index of the maximum capacity for glycolysis (Young et al. 1984, 1985).

\section{Quantitative measurement of glucose utilization}

Measurements of enzyme activities in vitro only provide an indication of the maximal flux through any metabolic pathway; they do not provide a measure of the actual flux in vivo. In an attempt to quantify glucose uptake by brown adipose tissue in vivo under a variety of physiological conditions, several groups (Kraegen et al. 1983; Ferré et al. 1985; Smith et al. 1986) have adopted the tracer 2-deoxyglucose technique originally used by Sokoloff et al. (1977) for estimating glucose uptake by the brain. The use of 2deoxyglucose as a tracer for glucose metabolism is dependent on the sugar analogue being transported from the plasma, by the specific membrane-associated glucose transporter, into the cytosol. It is phosphorylated by hexokinase to 2-deoxyglucose 6-phosphate, but this is not a substrate for phosphofructokinase, and the 2-deoxyglucose 6-phosphate accumulates within the cell.

Measurement of plasma 2-deoxyglucose radioactivity at intervals after the intravenous injection of a bolus of 2-deoxyglucose tracer allows a disappearance curve to be constructed. This is mirrored by the accumulation of labelled 2-deoxyglucose 6phosphate in the tissues; the whole-body accumulation curve is the sum of the individual curves of each discrete tissue. The rate of tissue glucose utilization can be calculated from the product of tissue 2-deoxyglucose 6-phosphate content and plasma glucose divided by the area under the plasma 2-deoxyglucose curve:

$$
\text { Rate }=\frac{\text { [tissue 2-deoxyglucose 6-phosphate] [plasma glucose] }}{\text { LC [area under plasma 2-deoxyglucose curve] }} .
$$

The inclusion of the dimensionless lumped constant (LC) is to account for the discrimination between glucose and 2-deoxyglucose by the glucose transport system and by hexokinase. Its value has been determined in a number of tissues in vitro and has been found to be between 0.6 and 1.0. Since the value of $L C$ in vivo is unknown, and may alter under physiological conditions (Pardridge, 1983), a value of 1.0 has been assumed in subsequent studies.

The technique is appropriate to all the peripheral glucose-consuming tissues such as muscle, adipose tissues and brain, but it is inappropriate for liver and kidney since in these tissues 2-deoxyglucose 6-phosphate is dephosphorylated by glucose-6-phosphatase (Walker, 1966). The technique allows an assessment to be made of the rate of glucose uptake by brown adipose tissue and, hence, an evaluation of both the potential 
contribution of glucose as a fuel for thermogenesis and the contribution of brown adipose tissue to the whole-body glucose-utilization rate.

\section{Effect of thermogenic stimuli on glucose uptake by brown adipose tissue in vivo}

Glucose uptake by brown adipose tissue in control $o b / o b$ mice is low, being less than $2 \%$ of the whole-body rate of glucose utilization. Both acute and chronic treatment with the thermogenic $\beta$-agonist BRL 26830 produced a significant increase in glucose uptake by brown adipose tissue and, in mice given the combined treatment, brown adipose tissue accounted for $12.5 \%$ of the whole-body rate of glucose utilization (Young et al. 1985). This contrasts with all other tissues studied, none of which showed a significant change. This treatment with BRL 26830 results also in a very significant improvement in glucose tolerance. In addition metabolic rate is increased by $0.5-1.0 \mathrm{~kJ} / \mathrm{h}$. The rate of glucose uptake by brown adipose tissue $(900 \mathrm{nmol} / \mathrm{min}$ per mouse) equates, if all the glucose was completely oxidized, to an increase in metabolic rate of $0.16 \mathrm{~kJ} / \mathrm{h}$ per mouse. Thus, in this genetic mutant, it is concluded that glucose utilization by brown adipose tissue can make a substantial short-term contribution to glucose homeostasis under strong thermogenic stimulus. Furthermore, it could theoretically, if all the glucose were oxidized, be a significant fuel for thermogenesis.

To investigate the effect of insulin more directly, warm- and cold-acclimated rats were examined under euglycaemic- and either normoinsulinaemic- or hyperinsulinaemicclamp conditions (Smith et al. 1986).

Cold acclimation of rats at $4^{\circ}$ for 3 weeks had no effect on the basal blood glucose concentration, but did produce a significant decrease in plasma insulin concentration. In these post-absorptive rats, under basal conditions, there were no differences in the whole-body rates of glucose production or glucose utilization between the warm- and cold-acclimated rats. However, when the plasma insulin concentration in the warmacclimated rats was raised by $50 \mu \mathrm{U} / \mathrm{ml}$, glucose utilization increased by $19 \%$ and the endogenous glucose production decreased by $8 \%$. In cold-acclimated rats, glucose utilization increased by $44 \%$ and endogenous glucose production decreased by $44 \%$. This effect occurred in spite of the fact that the plasma insulin concentration was lower in the cold-acclimated rats than in the warm-acclimated rats (Table 2).

Table 2. Effect of cold-acclimation and insulin on whole-body rates of glucose utilization and endogenous glucose production ( $\mu \mathrm{mol} / \mathrm{min}$ per rat)

(Male rats were housed at $23^{\circ}$ or $4^{\circ}$ for 3 weeks. All rats were fasted for $5 \mathrm{~h}$ at room temperature before undergoing the euglycaemic-clamp procedure. Values are means and standard deviations for six rats)

\begin{tabular}{|c|c|c|c|c|c|c|c|}
\hline \multirow{2}{*}{\multicolumn{2}{|c|}{ Treatment }} & \multicolumn{2}{|c|}{$\begin{array}{c}\text { Plasma } \\
\text { insulin } \\
(\mu \mathrm{U} / \mathrm{ml})\end{array}$} & \multicolumn{2}{|c|}{$\begin{array}{c}\text { Endogenous } \\
\text { glucose } \\
\text { production }\end{array}$} & \multicolumn{2}{|c|}{$\begin{array}{l}\text { Glucose } \\
\text { utilization }\end{array}$} \\
\hline & & Mean & $S D$ & Mean & SD & Mean & SD \\
\hline \multirow[t]{2}{*}{ Warm-acclimated } & Basal & 129 & 39 & $16 \cdot 8$ & $2 \cdot 5$ & $16 \cdot 8$ & $2 \cdot 5$ \\
\hline & Insulin & 181 & 61 & $13 \cdot 0$ & $2 \cdot 8$ & $20 \cdot 0$ & $2 \cdot 6$ \\
\hline \multirow[t]{2}{*}{ Cold-acclimated: } & Basal & $76^{*}$ & 33 & $18 \cdot 5$ & 2.9 & $18 \cdot 5$ & 2.9 \\
\hline & Insulin & 123 & 23 & $10 \cdot 5$ & 3.7 & $26 \cdot 7^{+} \ddagger$ & $4 \cdot 5$ \\
\hline
\end{tabular}

* Mean value was significantly different from that for warm-acclimated: basal treatment $(P<0.05)$.

+ Mean value was significantly different from that for warm-acclimated: insulin treatment $(P<0 \cdot 05)$. $\$$ Mean value was significantly different from that for cold-acclimated: basal treatment $(P<0 \cdot 01)$. 
Table 3. Tissue glucose metabolic indices (nmol/min per $g$ fresh weight) in vivo of warmand cold-acclimated rats

(Male rats were housed at $23^{\circ}$ or $4^{\circ}$ for 3 weeks. All rats were fasted for $5 \mathrm{~h}$ at room temperature before undergoing the euglycaemic-clamp procedure. Values are means and standard deviations for six rats)

\begin{tabular}{|c|c|c|c|c|c|c|c|c|}
\hline \multirow[b]{3}{*}{ Tissue } & \multicolumn{4}{|c|}{ Warm-acclimated } & \multicolumn{4}{|c|}{ Cold-acclimated } \\
\hline & \multicolumn{2}{|c|}{ Basal } & \multicolumn{2}{|c|}{$\begin{array}{l}\text { Insulin- } \\
\text { treated }\end{array}$} & \multicolumn{2}{|c|}{ Basal } & \multicolumn{2}{|c|}{$\begin{array}{l}\text { Insulin- } \\
\text { treated }\end{array}$} \\
\hline & Mean & $\mathrm{SD}$ & Mean & SD & Mean & $S D$ & Mean & SD \\
\hline $\begin{array}{l}\text { Interscapular brown adipose } \\
\text { tissue }\end{array}$ & 21 & 6 & 34 & 18 & $41+$ & 14 & $162 *+\dagger$ & 48 \\
\hline White adipose tissue & 20 & 8 & 25 & 9 & 14 & 8 & 19 & 6 \\
\hline Quadriceps muscle & 17 & 5 & 30 & 11 & 26 & 6 & 48 & 31 \\
\hline Heart & 284 & 1321 & $705^{*}$ & 157 & 474 & 158 & 863 & 42 \\
\hline Diaphragm & 85 & 33 & $156^{*}$ & 32 & 107 & 18 & $201^{*}$ & 65 \\
\hline
\end{tabular}

Mean values were significantly different from basal values at the same acclimation temperature: $* P<0.001$.

Mean values were significantly different from similarly treated warm-acclimated group: $+P<0 \cdot 01$, $\dagger+P<0 \cdot 001$.

The glucose metabolic indices for some key tissues are given in Table 3 . The tissue with the highest glucose metabolic index (per $g$ wet wt) is heart. In control warmacclimated rats, the index was 284 (SD 1321) nmol/min per $\mathrm{g}$. The metabolic index was increased significantly by both insulin and cold-acclimation. However, its contribution to whole-body glucose utilization was small, ranging from $2 \cdot 2$ to $4 \cdot 7 \%$.

Induction of physiological hyperinsulinaemia in warm-acclimated rats increased glucose utilization by some muscles (Table 3), but had no significant effect on brown adipose tissue. However, following cold acclimation, insulin had a highly selective effect on stimulating glucose uptake by brown adipose tissue.

In control, warm-acclimated rats the glucose metabolic index of interscapular brown adipose tissue was not significantly different from that of epididymal white adipose tissue. The basal glucose metabolic index was increased twofold in cold-acclimated rats, even though these rats had a lower plasma insulin concentration. Insulin treatment of cold-acclimated rats produced a further fourfold increase. Thus, in comparison with control warm-acclimated rats, which had similar plasma insulin concentrations (Table 2), the glucose metabolic index of the interscapular brown adipose tissue of the coldacclimated, insulin-treated rat was increased eightfold. Under the latter conditions, the contribution of total brown adipose tissue (assuming that it all behaves like interscapular brown adipose tissue) to the whole-body glucose utilization rate is $2.3 \%$. This is significantly more than brain and about half that of heart. Its contribution to the insulin-stimulated increase in glucose utilization in cold-acclimated rats was equivalent to that of the heart.

The contributions of brown adipose tissue to overall rates of glucose utilization in the rat are minor in comparison with muscle (16-23\%). However, the finding that the maximal activity of hexokinase in brown adipose tissue of cold-acclimated rats is of the order of $12 \mu \mathrm{mol} / \mathrm{min}$ per $\mathrm{g}$ (50- to 100 -fold higher than the measured rate of glucose utilization), suggests that under appropriate acute stimulation (e.g. higher concen- 
trations of insulin or noradrenaline, or both, or acute cold) further increases in glucose utilization are probable. It is also clear that in these cold-acclimated rats, which were studied $30 \mathrm{~min}$ after transfer to a warm environment, glucose utilization by brown adipose tissue makes a relatively insignificant contribution to basal and insulinstimulated metabolic rates. If all the glucose taken up by brown adipose tissue was totally oxidized to carbon dioxide then it would be equivalent to about $0.1 \mathrm{~kJ} / \mathrm{h}$, whereas the basal metabolic rate was $10 \mathrm{~kJ} / \mathrm{h}$. However, the selective increase in insulin sensitivity of brown adipose tissue relative to other tissues (Table 3) suggests that insulin-mediated processes are important in maintaining the capacity for increased non-shivering thermogenesis.

The glucose flux through brown adipose tissue and other major sites of glucose utilization has also been quantified in rats exhibiting high rates of thermogenesis. Since the techniques for quantifying these fluxes demand steady-state conditions, we have used the long-acting selective $\beta$-adrenoceptor agonist BRL 26830, rather than noradrenaline, to increase metabolic rate (Cawthorne et al. 1987). Acute treatment with BRL 26830 (5 $\mathrm{mg} / \mathrm{kg}$ intraperitoneally) produced a small reduction in the steady-state glucose concentrations (6.0 (SD 0.4) v. 5.1 (SD 0.2) $\mathrm{mM}$ for control and treated rats respectively $P<0.01)$. However, whole-body glucose utilization was not increased significantly $(19.3$ (SD 1.5) $\nu .20 .4$ (SD 1.8) $\mu \mathrm{mol} / \mathrm{min}$ ), although the metabolic clearance rate of glucose was significantly increased (32.3 (SD 2.2) v. 40.5 (SD 4.3) $\mathrm{ml} / \mathrm{min}$ per $\mathrm{kg}, P<0.01$ ). The effect of treatment with a thermogenic $\beta$-agonist on tissue rates of glucose utilization is shown in Table 4. Glucose utilization in brown adipose tissue was increased fifteenfold, but was nevertheless only a small $(<5 \%)$ component of the overall glucose utilization.

This conclusion is further supported by recent work by Ma \& Foster (1986) who measured directly from arterio-venous difference and blood flow determinations glucose uptake by brown adipose tissue of cold-acclimated rats in which thermogenesis was stimulated by an infusion of noradrenaline. The basal glucose uptake rate of brown adipose tissue was similar using the arterio-venous difference and 2-deoxyglucose technique. Noradrenaline infusion produced an eightyfold increase in glucose uptake. This was accompanied by increases in the output of lactate and pyruvate such that the contribution of glucose oxidation to thermogenesis at the maximal stimulatory dose of noradrenaline is only $2 \%$. Furthermore, even an eightyfold increase in glucose utilization by brown adipose tissue had little overall effect on whole-body rates of glucose utilization.

All these studies show that conditions that increase energy expenditure via a stimulation of brown adipose tissue also produce an increase in glucose utilization by

Table 4. Effect of acute treatment with the thermogenic $\beta$-agonist BRL 26830 on tissue rates of glucose utilization (nmol/min per $g$ fresh weight)

(Rats were fasted for $5 \mathrm{~h}$ before receiving $5 \mathrm{mg}$ BRL 26830/kg. Whole-body glucose utilization and tissue rates of 2-deoxyglucose uptake were measured $1 \mathrm{~h}$ after dosing. Results are means and standard deviations for six rats)

\begin{tabular}{|c|c|c|c|c|c|}
\hline \multirow[b]{2}{*}{ Tissue } & \multicolumn{2}{|c|}{ Control } & \multicolumn{2}{|c|}{ BRL 26830-treated } & \multirow{2}{*}{$\begin{array}{c}\text { Statistical } \\
\text { significance } \\
\text { of difference }\end{array}$} \\
\hline & Mean & SD & Mean & SD & \\
\hline Interscapular brown adipose tissue & 22 & 5 & 333 & 198 & $P<0.01$ \\
\hline White adipose tissue & 18 & 5 & 34 & 18 & \\
\hline Quadriceps & 12 & 3 & 19 & 10 & \\
\hline Soleus & 22 & 8 & 57 & 21 & $P<0.01$ \\
\hline
\end{tabular}


brown adipose tissue. Furthermore, conditions that lead to an increase in thermogenic capacity also result in a selective increase in the insulin sensitivity of brown adipose tissue. Even though brown adipose tissue glucose uptake and oxidation cannot make a significant contribution to the thermogenic fuel, it is likely that glucose utilization by brown adipose tissue is critically important in the generation of the thermic response. It is suggested that the insulin-mediated glucose uptake is anaplerotic to maintain pools of glycolytic and citric acid cycle intermediates as well as providing a source of glycerol phosphate for free fatty acid esterification and triglyceride synthesis.

\section{Decreased glucose utilization in brown adipose tissue and the development of impaired glucose tolerance}

Although studies on glucose utilization in animals given thermogenic stimuli do not in general support the idea that the brown adipose tissue makes a significant contribution to glucose homeostasis, the possibility still exists that defective glucose utilization in brown adipose tissue in insulin-resistant models might account for the development of diabetes. Indeed, a number of animal models do demonstrate an early development of an insulin-resistant state in brown adipose tissue. However, quantitative studies on wholebody and tissue glucose utilization rates, using physiological concentrations of insulin in rats fed on a high-fat diet (Storlien et al. 1986; Kraegen et al. 1986), show that brown adipose tissue cannot account for the fall in whole-body rates of glucose utilization. Similar conclusions can be drawn from studies on lactating rats and obese Zucker rats (Ferré et al. 1986).

\section{Insulin resistance in brown adipose tissue}

A large number of studies have shown that rodent models of diabesity exhibit an early hyperinsulinaemia followed by insulin resistance. In addition it is now becoming evident that insulin resistance does not develop coincidentally in all tissues, and temporarily occurs earliest in brown adipose tissue. Furthermore, of all the tissues in rodents, brown adipose tissue shows the largest increase in responsiveness with respect to physiological changes in the insulin concentration. These findings lead to the hypothesis that the early hyperinsulinaemia, coupled with the high responsiveness of brown adipose tissue to insulin in pre-obese animals, leads to an over-supply of glucose in relation to its needs. The development of insulin resistance in brown adipose tissue may be an important protective mechanism to prevent a continual over-supply of glucose, which will be stored as glycogen and triacylglyceride. If a high rate of glucose utilization is essential for expression of a normal thermic response (to cold or food), then this insulin resistance might be a causal factor in the development of obesity. If such suggestions are correct then one might expect agents that improve insulin sensitivity in animals to restore thermogenic activity in situations in which it is defective.

Mercer \& Trayhurn (1984) showed that a loss of thermogenic responsiveness to cold in $o b / o b$ mice developed between 26 and $35 \mathrm{~d}$ of age. This coincided with the development of insulin resistance as determined by alterations in the stimulation by insulin of lipogenesis. Treatment of $o b / o b$ mice with a compound called ciglitazone, which improves diabetic control in a range of animal models (Chang et al. 1983a,b,c), not only restored insulin sensitivity, but also restored the ability of cold to acutely increase GDP binding to brown adipose tissue mitochondria, which is believed to be an index of thermogenic activity (Mercer \& Trayhurn, 1986). In other studies, Thurlby et al. (1987) found that chronic treatment of normal adult mice with ciglitazone increased the amount of brown adipose tissue mitochondrial protein and total GDP binding very significantly. Furthermore, whilst having no stimulatory effect itself on the metabolic rate of the mice, 
it allowed a significant enhancement of the thermogenic response to the $\beta$-agonist BRL 26830. In similar studies in rats, Rothwell et al. (1987) have shown enhanced thermogenic responses to a $40 \mathrm{~kJ}$ intragastric meal of carbohydrate in ciglitazone-treated rats. However, the thermic response to a $40 \mathrm{~kJ}$ fat load was not affected. Such studies support the theory concerning the essential anaplerotic role of glucose utilization in the development of a thermic response.

Ciglitazone and a number of agents that improve insulin sensitivity also produce brown adipose tissue hypertrophy (Thurlby et al. 1987; Sohda et al. 1982). This suggests that the synthesis or degradation, or both, of brown adipose tissue proteins, including the $32 \mathrm{kDa}$ uncoupling protein, might be regulated also by insulin.

\section{Brown adipose tissue in man}

In humans the role of BAT as an effector of non-shivering thermogenesis has not been clearly established, and it is possible that muscle is the principal effector. Nevertheless, there is now evidence that normal sensitivity to insulin is required for thermogenesis following either a glucose lead or a mixed meal. Thus, older subjects have a reduced thermogenic response to glucose relative to young subjects (Golay et al. 1983), and there is a reduced response in both obese and diabetic subjects in relation to the degree of glucose intolerance (Golay et al. 1982). The possibility that these reduced responses are related to insulin sensitivity rather than the plasma insulin concentration has recently been confirmed in similar groups of obese and diabetic patients by the demonstration of a correlation between rate of glucose uptake and net change in energy expenditure under euglycaemic-insulin-clamp conditions (Golay et al. 1986).

The normal thermogenic response to a meal of glucose in man is $10 \%$ of the energy content of the meal and, therefore, differences in the thermogenic response between normal and insulin-resistant subjects are small. Nevertheless, the cumulative effect of such a difference in energy expenditure could have an influence on the development of human obesity as it does in rodents.

\section{Conclusions and speculations}

(1) Brown adipose tissue glucose metabolism is modified selectively by insulin according to the physiological status of the animal: impaired in insulin-resistant animals, and increased in insulin-sensitive animals.

(2) Noradrenaline and thermogenic $\beta$-agonists stimulate glucose uptake by brown adipose tissue.

(3) Increased glucose uptake by brown adipose tissue supports thermogenesis but glucose is not a major fuel (with the possible exception of $o b / o b$ mice given $\beta$-agonists).

(4) Glucose utilization by brown adipose tissue is probably not important in the direct regulation of blood glucose concentrations.

(5) Changes in insulin sensitivity of brown adipose tissue may modulate the ability to activate thermogenesis both through short-term effects on glucose flux into brown adipose tissue and through longer-term effects on the amount of mitochondrial proteins, particularly uncoupling protein. Thus, the development of insulin resistance may be a fundamental defect in the development of obesity as well as in diabetes. 


\section{REFERENCES}

Arch, J. R. S., Ainsworth, A. T., Cawthorne, M. A., Piercy, V., Sennitt, M. V., Thody, V. E., Wilson, C. \& Wilson, S. (1984). Nature 309, 163-165.

Carroll, M. J., Lister, C. A., Sennitt, M. V., Stewart-Long, N. \& Cawthorne, M. A. (1985). Diabetes 34, 1198-1204.

Cawthorne, M. A., Smith, S. A. \& Young, P. (1987). In Recent Advances in Obesity Research, vol. 5, pp. 312-318 [E. M. Berry, S. H. Blondheim, H. E. Eliahon and E. Shafrir, editors]. London: John Libbey.

Chang, A. Y., Gilchrist, B. J. \& Wyse, B. M. (1983a). Diabetologia 25, 514-520.

Chang, A. Y., Wyse, B. M. \& Gilchrist, B. J. (1983b). Diabetes 32, 839-845.

Chang, A. Y., Wyse, B. M., Gilchrist, B. J., Peterson, T. \& Diani, A. R. (1983c). Diabetes 32, 830-838.

Cooney, G. J. \& Newsholme, E. A. (1982). FEBS Letters 148, 198-200.

Cooney, G. J. \& Newsholme, E. A. (1984). Trends in Biochemical Sciences 9, 303-305.

Ferre, P., Leturque, A., Burnol, A. F., Penicaud, L. \& Girard, J. (1985). Biochemical Journal 228, 103-110.

Ferre, P., Burnol, A. F., Leturque, A., Terrataz, J., Penicaud, L., Jeanrenaud, B. \& Girard, J. (1986). Biochemical Journal 233, 249-252.

Golay, A., Schutz, Y., Broquet, C., Moeri, R., Felber, J. P. \& Jequier, E. (1983). Joumal of the American Geriatric Society 31, 144-148.

Golay, A., Schutz, Y., Felber, J. P., De Fronzo, R. A. \& Jequier, E. (1986). International Journal of Obesity $10,107-116$.

Golay, A., Schutz, Y., Meyer, H. U., Thiebaud, D., Churchod, B., Maeder, E., Felber, J. P. \& Jequier, E. (1982). Diabetes 31, 1023-1028.

James, W. P. T. \& Trayhurn, P. (1976). Lancet ỉ, 770-773.

Kraegen, E. W., James, D. E., Bennett, S. P. \& Chisholm, D. J. (1983). American Journal of Physiology 245, E1-E7.

Kraegen, E. W., James, D. E., Storlien, L. H., Burleigh, K. M. \& Chisholm, D. J. (1986). Diabetologia 29, 192-198.

Ma, S. W. Y. \& Foster, D. O. (1986). Canadian Journal of Physiology and Pharmacology 64, 609-614.

McCormack, J. G. \& Denton, R. M. (1977). Biochemical Journal 166, 627-630.

Mercer, S. W. \& Trayhurn, P. (1984). Biosciences Report 4, 933-940.

Mercer, S. W. \& Trayhurn, P. (1986). FEBS Letters 195, 12-16.

Pardridge, W. M. (1983). Physiological Reviews 63, 1481-1535.

Rothwell, N. J. \& Stock, M. J. (1982). British Journal of Nutrition 47, 461-471.

Rothwell, N. J. \& Stock, M. J. (1983). International Journal of Obesity 7, 583-589.

Rothwell, N. J., Stock, M. J. \& Tedstone, A. E. (1987). Molecular and Cell Endocrinology 57, 253-257.

Sennitt, M. V., Arch, J. R. S., Levy, A. L., Simson, D. L., Smith, S. A. \& Cawthorne, M. A. (1985). Biochemical Pharmacology 34, 1279-1285.

Smith, S. A., Young, P. \& Cawthorne, M. A. (1986). Biochemical Journal 237, 789-795.

Sohda, T., Mizuno, K., Imamiya, E., Sugiyama, Y., Fujita, T. \& Kawamatsu, Y. (1982). Chemical Pharmacology Bulletin 30, 3580-3600.

Sokoloff, L., Reivich, M., Kennedy, C., Des Rosiers, M. H., Patlak, S. C., Pettigrew, K. D., Sakurada, O. \& Shinohara, M. (1977). Journal of Neurochemistry 28, 897-916.

Storlien, L. H., James, D. E., Burleigh, K. M., Chisholm, D. J. \& Kraegen, E. W. (1986). American Journal of Physiology 251, E576-E583.

Thurlby, P. L. \& Trayhurn, P. (1979). British Journal of Nutrition 42, 377-385.

Thurlby, P. L. \& Trayhurn, P. (1980). Pfilgers Archiv 385, 193-201.

Thurlby, P. L., Wilson, S. \& Arch, J. R. S. (1987). Bioscience Reports 7, 573-577.

Trayhurn, P. (1979). Pfiugers Archiv 380, 227-232.

Walker, D. G. (1966). In Essays in Biochemistry, vol. 2, pp. 33-67 [P. N. Campbell and G. D. Greville, editors]. New York: Academic Press.

Young, P., Cawthorne, M. A., Levy, A. L. \& Wilson, K. (1984). FEBS Letters 176, 16-20.

Young, P., Cawthorne, M. A. \& Smith, S. A. (1985). Biochemical and Biophysical Research Communications 130, 241-248. 